RUSSELL TYTLER AND DALENE SWANSON

\title{
UNPACKING THE PURPOSES AND POTENTIAL OF INTERDISCIPLINARY STEM
}

\begin{abstract}
This chapter traces the development of STEM advocacy as a globalizing modernist discourse based in national competitive wealth creation agendas. It therefore addresses the drivers for STEM in schools by way of understanding state and industry intentions and curriculum reform. The chapter describes a dual research program consisting of an examination of research, policy and public literatures, as well as an exploration of teacher and student discourses and experiences of interdisciplinary STEM in two schools. The latter exploration seeks to understand the catalysts of policy advocacy for interdisciplinary STEM in schools; the promises and challenges of interdisciplinary STEM practice; and the relation of STEM to individual STEM subjects. From the document analysis, the chapter argues that STEM is a complex construct that in its implementation in schools is captive to a range of subject and schooling political agendas. Analysis of STEM advocacy uncovered a number of key drivers, including: wealth creation; STEM as a powerful 'meta-discipline'; innovation and critical thinking; and advocacy of interdisciplinary STEM as 'skills' preparation for work futures and everyday life. Examples of interdisciplinary curriculum practice in two case schools illustrated a number of themes: student engagement with new ways of thinking as a driver of change; development of more student-centred, project-based pedagogies; student engagement in deeper learning of disciplinary knowledge through meaningful problems-solving; and, the importance of temporal relations between subjects as they are conscripted to solving authentic problems. Finally, the chapter addresses the contradictory nature of STEM advocacy; that it represents, on the one hand, a narrowing utilitarian conception of curriculum that leads us away from notions of education as the development of personhood, but, on the other hand, that it opens up possibilities for more meaningful engagement of students in learning for ethical and productive lives. The chapter argues that interdisciplinarity is most advantageously practiced in terms of temporal relations between distinct STEM disciplines rather than as an undifferentiated meta-disciplinary amalgam of these distinctive ways of practising and knowing. In this sense, an argument is presented that the key challenge for STEM education is to reform STEM subject pedagogies to more meaningfully represent disciplinary epistemic practices in authentic interdisciplinary settings. These arguments have implications for international STEM education and for global advocacies of interdisciplinarity in STEM.
\end{abstract}

To be published in $\mathrm{n}$ : Mansour $\mathrm{N}$ \& El-Deghaidy $\mathrm{H}$ (eds.) STEM in Science Education and S in STEM: From pedagogy to learning. Leiden: Brill Publishers 


\section{INTRODUCTION}

In recent decades, STEM has increasingly become a new frontier for the advancement of globalising economic modernisation within the New Knowledge Economy. Combining Science, Technology, Engineering and Mathematics as a new distinct discourse of STEM, positions STEM as more than a set of academic subjects. It functions in a number of ways: to bring together a number of discourses or disciplines under the umbrella of 'STEM', while recognising their distinctiveness in terms of theoretical influences, academic community, disciplinary rules, legacy and purposes; to offer a way of expressing their close relationship to each other; to provide distinction between them as a related set of discourses and other discourses, such as those within the Arts, Humanities, or Social Sciences; but also to promote the instrumental facilitation of a techno-scientific economic utilitarianism within existing global relations. STEM therefore functions as a dominant discourse, which is political in nature, despite claims to scientific neutrality. With this increasing global discursive dominance, there has been increasing concern raised internationally about the engagement of students, and the population more generally, in STEM-related study. This concern traverses the educational spectrum and includes students' engagement in STEM in post-compulsory years and beyond into STEM-related professions (Marginson, Tytler, Freeman \& Roberts. 2013).

A large measure of these concerns, at policy level, are driven by increasing claims to the centrality of STEM skills and knowledge, and STEM-based innovation, to national wealth creation (Office of the Chief Scientist, 2013; COSEPUP, 2006). This is a global phenomenon and reflects a recent push to centralise STEM in schools, where it is commonly argued that success in STEM within national curricular assessment regimes is a core determinant of a nation state's future international economic competitiveness and a necessary driver for economic growth. Through STEM study, students in schools are positioned as the next generation of a labour force serving the ambitions of that nation state in competition with other nations within a global marketplace. This is no longer only prevalent in the Western-world but has become worldwide as globalising modernism spreads across almost every part of the globe (Swanson, 2013a).

In Scotland, where one author resides and researches, the push for STEM study has become a crisis response to a recent Organisation for Economic Cooperation and Development (OECD) report on Scotland (OECD, 2015), which asserts purported 'weaknesses' in the Scottish schooling system in comparison with other European educational systems. This move has also sounded the beginning of a reversal in trend, towards greater conservatism and conventionalism, from an earlier move towards greater openness and progressivism in national curricular development (Swanson, Yu and Mouroutsou, 2017). Alarmist discourses have also seen funding directed towards numeracy and literacy in schools, and away from the arts, in many instances. Here, numeracy and literacy are seen as critical to Scotland's economic 
survival, especially under the uncertainties and precarities proliferated by Brexit and, more widely, the UK government's continuing policy of economic austerity (Coppola, 2018).

In Australia, where the other author resides and researches, the STEM policy focus is also linked to concerns about declining relative performance of Australian students on international tests, and indeed a suggested decline in absolute standards in mathematics and literacy particularly (Thomson, De Bortoli \& Underwood, 2017). In South Africa, a context in which one of the authors has previously resided and researched, rhetoric on the 'STEM crisis' has reached fever pitch in the media and in policy discourses. Youth, especially unemployed youth, are held responsible for dampening national economic prospects, rather than the responsibility lying with the South African state for ineptitude and failures in governance, including the lack of political will to address burgeoning inequality (Swanson, 2013b).

Crisis rhetoric on STEM is therefore not only a minority world phenomenon, but also finds its way into majority world contexts, and techno-scientific rationalism is prevalent within economic development discourses (Swanson, 2017; Swanson, 2013b). Engagement with STEM at the conceptual level is part of this mix of concerns about student participation, but also about overall student performance. These concerns are, of course, fuelled through the rise and prominence of international league tables such as PISA and TIMSS, which pit one nation against another by comparing the achievements of its youth. Comparative national performance in STEM is a strong driver of educational policy in Australia, for instance, and has a history of influence in countries such as Germany, Japan and the US. Recent interest in the Finnish education system derives from similar concerns (Marginson et al., 2013). By drawing a direct link between youth participation and performance in STEM (as well as literacy levels), and economic productivity and competitiveness of a nation state, STEM performance and capacity becomes the litmus paper through which a nation views itself and by which it legitimates selfjudgement in accordance with an economic modernist agenda. STEM education, therefore, as a dominant discourse of economic development is no longer simply an educational matter, but it has been reified to a level of political importance that acts as a defining national agenda item in itself. In this sense, a modernist 'futures' discourse on STEM education has become such that national achievements in STEM have arguably become pivotal to a nation's sense of self-worth, achievement and power beyond only economic potential.

In global context, policy and practice concerns about student participation and conceptual engagement with STEM disciplines and associated subjects in schools and post-secondary institutions have become a unified discourse. In response, there has been increasing interest in and advocacy of STEM as an interdisciplinary phenomenon. Encouraged by the increasing currency of the acronym itself, a substantial part of the meaning of 'STEM', in policy and curriculum speak, is the structuring of an assumption that STEM can be defined as a coherent entity with its own distinct conceptual characteristics, including skills and epistemic forms and practices (Tytler, Swanson, and Appelbaum, 2015). In schools, and in much public curriculum advocacy, 'STEM' has become associated with particular practices that 
foreground project-based learning, 'authentic' problems and competencies or skills that are argued to prepare students for productive engagement with the realities of ' $21^{\text {st }}$ century work', develop scientific literacy for everyday life situations and increase participation in science-related activity. There are also arguments that particular critical and creative interdisciplinary orientations to STEM engagement in schools and society can foster contributions to ethical and social wellbeing and address challenges of a local and global nature. Therefore, there are reasons to engage with advocacies for STEM beyond economic utilitarianism, national pride, or global competitiveness, and view the epistemological importance of STEM in a wider context that fosters ethical dispositions in scientific praxis.

In light of this recent history of STEM at this juncture of globalising modernism, this chapter addresses the following research questions through an examination of literature on interdisciplinary STEM, including a review of public advocacy documents:

1. What are the catalysts of advocacy for increased attention to STEM in schools?

2. What are the catalysts of advocacy for interdisciplinary STEM curricular practices?

Secondly, further questions explore how this policy advocacy and public engagement are embraced in schools, through case studies of interdisciplinary STEM practices in these educational settings. These questions are:

3. What are the drivers within schools for interdisciplinary STEM?

4. What are the promises and challenges of interdisciplinary STEM curriculum activity?

Finally, from both sets of data, a further analysis is framed by the following question:

5. How is interdisciplinary STEM conceptualised in relation to the individual STEM subjects?

The case studies, which refer to work in which one of the authors has been involved, published elsewhere (Tytler, Williams, Hobbs \& Anderson, in press), are drawn from schools involved in two major Australian STEM initiatives. In each of these initiatives, at least 12 schools were involved with workshop intensives where teachers of science, mathematics and technology were inducted into contemporary conceptions of STEM teaching, in the individual disciplines but also in interdisciplinary settings. Teachers from these schools planned and implemented curricular innovations designed to promote student engagement with STEM, supported by further workshops and by mentors assigned to visit the schools. The case studies, of two schools (A and B), one from each professional development (PD) initiative, were constructed from a range of data, including interviews with teachers, school leaders and students, but they also included student-produced artefacts, fieldnotes at workshops, and school-planning documents. The case studies are not reported on fully in this paper, but data from the two schools are drawn upon to illustrate certain relevant points and provide perspectives on key arguments.

The main focus of analysis is the Australian context, which acts as an exemplar for discussion on other global contexts for which there are wider implications. In 
Australia, as elsewhere, there is concern at policy level about diminishing student engagement with post-compulsory STEM, falling performance level on TIMSS and PISA (comparatively but also in absolute scores), but also about maintaining Australia's STEM workforce. The STEM agenda at national level achieved prominence through advocacy of the previous chief scientist, Ian Chubb (Office of the Chief Scientist, 2013), and recently STEM has been a major driver of curriculum reform in all Australian states and increasingly in schools.

A review of documents opens the discussion.

\section{DOCUMENT REVIEW: STEM EDUCATION AND INTERDISCIPLINARITY}

Rather than simply reviewing the academic literature on STEM Education, a review of a wider range of documents that represent government, institution and public policy advocacy of STEM is undertaken. The purpose is to explore the range of arguments in the promotion of STEM Education as well as the nature and advocacy of interdisciplinary STEM Education. The more detailed questions underpinning the document search are:

1. What is the dominant assumption underpinning a definition of STEM, and what variation is there in how the term is used in relation to the individual STEM disciplines?

2. What are the dominant arguments for a strong STEM focus, and who are the main groups making these arguments?

3. How is STEM conflated (or not) at the school level with Science and/or Mathematics, and what is the nature of advocacy for engineering and technology?

4. What skills and knowledge are advocated as a focus for a school STEM curriculum?

5. What is the nature of critiques of the current push for interdisciplinary STEM?

The document sources included are:

- STEM Education research literature concerning the nature of interdisciplinarity in STEM curricula and its relationship to disciplinary epistemic and pedagogic processes, and research on student and teacher learning through STEM;

- public documents including white papers and press releases from key policy figures such as the Australian chief scientist, and policy analyses from institutes and STEM organisations;

- websites associated with major STEM projects and organisations promoting STEM; and

- public communications such as publicity for STEM workshops and conferences, media interviews with key education and science figures, and opinion pieces in newspapers and online media outlets.

The analysis involves reviewing each document for its relevance to the questions, and under each question developing themes that represented major strands of thinking and advocacy about STEM, including interdisciplinary STEM. Below the 
TYTLER \& SWANSON

findings under these themes are presented. The first theme relates to what is meant by 'STEM' in a curricular sense.

\section{The nature of STEM in relation to the individual STEM disciplines}

With regard to the question of how it relates to the individual STEM disciplines or school subjects (research questions $4 \& 5$ [RQ4,5]), the STEM construct is not straightforward in its application across the spectrum from research and development to school curricula (Marginson et al., 2013). In schools, a core focus of attention is on mathematics and science as the high status and 'enabling' STEM subjects. These key subjects tend to be promoted as the touchstones of STEM in schools. This is probably also as a result of the fact that mathematics and science are classical school subjects with a long history in schooling, long before the acronym of STEM was derived. Consequently, the most well-studied, integrated STEM education pairing is still that of mathematics and science (Berlin \& Lee, 2003; Berlin \& Lee, 2005). The U.S National Research Council (2009, p. 150) argued that "despite all of the concerns by policy makers, educators, and people in industry about the quality of U.S. K-12 STEM education, the role of technology education and engineering education have hardly been mentioned".

Thus, part of the difficulty in promoting STEM as a coherent entity, particularly an interdisciplinary entity, is the policy and public attention accorded to mathematics and science as the high-status grouping within the STEM stable. Further, it is sometimes assumed that engineering and technology can be covered within mathematics and science curricula (Herschbach, 2011) and consequentially become subsets of these disciplines. There is an interest in "retooling" the STEM subject fields in order to share instructional space with technology and engineering subjects (Moyer-Packenham, Anastasis, Johanna, Faye, \& Irby, 2008). English and King (2015) argue that engineering, particularly engineering design and thinking, should appear as a foundational process of integrative STEM, yet in secondary schools specific emphasis on 'engineering education' is not widely found (Tytler, Swanson, and Appelbaum, 2015). English (2016) argues that STEM programs can engage students via hands-on engineering design projects that help promote students' curiosity and interest in science study. In the US, engineering cross-cutting concepts are a strong feature of the US Next Generation Science Standards (NGSS), yet it is argued that school curricula do not capitalise on engineering design and thinking sufficiently (NGSS, 2014). It is not surprising then when English (2016a) argues that learning outcomes for engineering within integrated STEM programs are underresearched.

Historically, there have been influential calls for integration of technology with science. Particularly, under the vision of "Science for All", Fensham (1985) argued for this integration on the basis that applied science and technology are evidenced in new products and new forms of communication. After all, globalization discourses are hinged on the integration of science, technology and telecommunications. Following this thinking, Fensham's forecast for technology as the new skill has 
foreshadowed current STEM advocacy on the basis of workplace skills and wealth creation.

Since these discussions, however, digital technologies, rather than those envisioned by Fensham, have been promoted as being crucially important, not only in shaping the way we interact with each other and with knowledge access and production as well as with 'learning processes', but also in the changing landscape of work. In an Australian report on employment futures (Hajkowicz et al., 2016), the critical importance of digital literacy skills for future workplaces and citizens was emphasized. In schools globally, increasingly teaching and learning utilizes digital resources, including learning management software, personal devices, and data probes. In the STEM case study programs, digital technology was promoted in schools as part of the ' $\mathrm{T}$ ' in STEM. In some cases, this involved cross-subject planning to create a developmental digital technology map charting progression across the middle secondary years. In other cases, units or activities were developed focused on coding or robotics, or incorporating software applications within interdisciplinary settings. Importantly, in each of these cases, while activities may have appeared to align with the narrower economic rationalism of globalization in promoting technology in STEM study, this was not attended to in a narrow sense and the interdisciplinary nature of the activities attested to a wider set of purposes in fulfilling student development beyond economic interests only.

To summarise, STEM is not a straightforward construct, either in terms of its definition in policy discourses or in practices in schools. In the latter case, STEM is interpreted by schools in complex ways, particularly in relation to the status imbalance between STEM subjects, the historical silence of engineering in school curricula, ambiguity about the meaning of 'technology' alongside a fast-changing landscape for digital technologies in schools, and a historical lack of enthusiasm for integrating the STEM subjects.

\section{Catalysts for STEM advocacy}

In addressing the first two research questions $(\mathrm{RQ} 1,2)$ to our analyses in this chapter, the catalysts for STEM advocacy, the document review revealed a number of key themes: wealth creation; claims to coherence within the STEM construct; innovation and critical thinking; and advocacy of interdisciplinary STEM as skills preparation for work futures and everyday life. Each of these are described below.

\section{Wealth creation}

The arguments for STEM foci in research and education are well rehearsed and widely recognized, and, as noted earlier, are common across both majority and minority world contexts (Marginson et al., 2013). Chief among these is the economic utilitarian argument. In this dominant view, STEM occupations are argued to be critical to national wealth creation, and that shifting patterns of work, it is widely argued, make it increasingly urgent to create a population with STEM skills. In forwarding these arguments, what is common is the engagement with quantification of existing data and the embrace of statistical projections with a financial emphasis 
to legitimise such perspectives. For example, Australia's Chief Scientist reports that 75 percent of the fastest growing occupations require STEM skills (Office of the Chief Scientist, March 2014). In the same modality of advocacy, estimates have been advanced that shifting just $1 \%$ of the workforce into STEM roles would add \$57 billion to GDP over 20 years (PwC Australia, 2015). In this vein, it is argued that a strong STEM focus is crucial for a modern business complex (Perryman, July, 2014).

Adding to this argument for increasing dependence of national wealth on STEMrelated jobs is a stated concern for a looming shortage of STEM professionals. Olson and Gerardi, (February 2012) have claimed that the US needs to produce approximately 1 million more STEM professionals over the next decade than are projected to graduate at current rates (Lacey \& Wright, 2009; Langdon, McKittrick, Beede, Khan, \& Doms, 2011) if the country is to retain its historical preeminence in science and technology. To target this aim, it is claimed that the US needs to achieve a significant increase in the number of STEM graduates, an estimated increase of about 34\% annually. The fixation with supply of engineering graduates is well established in the US, for instance in talk of a 'gathering storm' in the COSEPUP (2006) report about the relative proportional number of engineers graduating from the US compared to China, which at the time was less than 1:8. It is not insignificant that in these prominent reports the US is compared to China, as this provides testimony to the fact that STEM is framed within parlance relating to globalizing competition and has become a key referent of national economic advantage. China is the main superpower that the US is most fearful of in terms of its threat to surpass the US as the dominant global economic power (Duncan, 2014).

These arguments are framed within competition fuelled by economic globalization, yet they are not without their contradictions and contestations. While many speak in alarmist terms about STEM skill shortages (see, Duncan, 2014), others question the employment angle with respect to the focus on STEM, pointing out an apparent oversupply of STEM graduates in relation to the total STEM workforce (Brown et al. 2012, p. 38).

\section{STEM as a powerful meta-discipline}

Advocacy of STEM as a coherent entity involves claims that it represents more than the sum of Science, Technology, Engineering and Mathematics. The U.S STEM School Education Strategy 2016-2026 report (Education Council, 2015) argues that the four elements support each other and integrate into a united concept by virtue of their intersecting use. For instance, it is argued that empirical evidence-based science generates new knowledge, which informs the engineering design process (Honey, Pearson, \& Schweingruber, 2014). The American National Science Foundation also reports STEM as a way to encompass a new "meta-discipline" that combines the four disciplinary areas. Nevertheless, as we will argue in the following section, there are cogent reasons for questioning the epistemic viability of the STEM 'metadiscipline' construct, and the combination of subjects may have more to do with political convenience related to perceived economic and industrial needs of the nation state than any 'natural' alignment. The difficulty in bringing STEM disciplines together under one epistemic category is reflected somewhat in the 
difficulty schools find in merging the subject areas of science, technology and mathematics into a coherent curriculum.

\section{Developing innovation and critical thinking}

Allied to the promotion of the STEM construct as representing a coherent curriculum entity, is the growing view that there is a set of STEM skills that are critical to boosting international competitiveness and national wellbeing. This rhetoric again brings together nationalist discourses alongside economic utilitarianism, to be conflated under STEM advocacy. In this sense, capitalist relations inform both global competitiveness and national wellbeing. Perryman (2014) argues that STEM knowledge and skills lead to new products, more efficient services, and a more diverse, resilient and sustainable economy. STEM skills are claimed to be increasingly critical to the workforce of the future (Australian Government, 2015; Commonwealth Bank, 2017). On the personal side of this advocacy, it is argued that individual citizens will need STEM knowledge and skills to survive in the future workplace: "Workers will use the foundational skills of mathematics and science for 9 hours a week (up 80 per cent from today) and advanced technology skills for 7 hours a week (also up 75 per cent from today)" (FYA, 2017, p.7). Again, not everyone agrees with this assessment. Rumbens (2015) reports that the most important skills for the workforce required by Australian employers, based on survey results, is the ability to actively learn on the job, engage in critical thinking and complex problem-solving, and to possess the capabilities for creative problem-solving. In analysing the language framing advocacy of STEM around these arguments, STEM is claimed to be imbued with these defining attributes and carries the necessary capacities to enable them. In an attempt to counter this dominant view, the humanities and social sciences (HASS) and arts also have been promoted from some quarters as enabling innovation and critical thinking necessary for contemporary life in the context of global crises. In support of this viewpoint, a STEM-HASS mix is being advocated.

In many countries, there is also interest in combining the STEM disciplines with the arts to create the acronym 'STEAM' (Marginson et al., 2013). The 'A' for Arts is often associated with design thinking. This is intended to emphasise the creative aspects of work in the STEM disciplines. Other combinations also abound. Questioning the exclusive association of higher-level skills with STEM, Sundararajan (2017) argues that "as the cognitive capabilities of digital machines expand, students may need less education in science, technology, engineering, and math and may benefit from a greater emphasis on design thinking, entrepreneurship, and creativity to prepare them for a micro-entrepreneurial career" (p.11). Outside of a singular economic focus, we could also argue that critical or political literacies are of equal importance to STEM skills given our current global threats, such burgeoning global inequality, ecological degradation, climate change, the negative potential of artificial intelligence, election-influencing algorithms embedded in social media platforms, amongst other issues, especially in what is increasingly being referred to as a 'post-truth' world. Nevertheless, the prevailing rhetoric emanating from governments, industry and some media is that STEM is the defining 
determinant of economic wellbeing of the nation state, and the primary pathway through which higher order thinking, ingenuity and problem-solving skills, purportedly necessary for economic growth, can be ensured for the nation's youth.

Hilton (2010) argues that in the $21^{\text {st }}$ century, there is a dramatically increased demand for a workforce possessing intellectual skills and abilities such as "adaptability, complex communications, non-routine problem solving, selfmanagement, and systems thinking". This is consistent with Bybee's (2013) claim that the workplace in the $21^{\text {st }}$ century has become more analytical and technical and that interconnected STEM skills play a vital role in supporting the entry requirements for the contemporary workforce.

Bybee (2013) further argues that with global changes come associated problems such as global climate change, ecological scarcity, and emerging and re-emerging infectious diseases. One argument is that these global issues have a strong relation to STEM disciplines because these disciplines and the skills gained from their study provide insights, explanations, and potential solutions that help citizens to better perceive their role in relation to global sustainability challenges. These examples also highlight the need for critical consciousness, political responsibility and ethics in STEM advocacy and perception, rather than a sole emphasis on economics and competition. This critical emphasis arguably underscores the need for an interdisciplinary STEM that has wider purposes and potentialities than narrowly entrepreneurial ones.

\section{Interdisciplinarity and 'STEM skills'}

An argument has been presented, thus far, that the dominant advocacy for STEM Education as a distinctive entity has two major components: first, the purported need to generate professionals in the specific areas of Science, Technology, Engineering and Mathematics who supply the wealth creation needs of the nation state; second, the needs of the contemporary state more generally to have a citizenry with the skills deemed to be important for contemporary industries to thrive, and important for individuals to meet the challenges of future workplaces and everyday life situations in a changing world. This last aspect, while closely aligned with the instrumentalist argument based on the need for an appropriately skilled workforce, signals a concern to frame an education that will attend to the future wellbeing of citizens, albeit in terms of work futures and productive participation in national wealth creation agendas, but also in terms of productive participation in global justice debates more generally (Bybee, 2013; Swanson, Yu and Mouroutsou, 2017).

Paradoxically then, with its focus on skills that prepare individuals for productive futures, STEM advocacy has opened the possibility for a reconsideration of the nature and purposes of STEM subjects. The concern to have more youth choose pathways in science and mathematics in school as well as STEM post-compulsory pathways does not necessarily signal the need for changes to these distinct, traditional subjects. However, three related concerns carry within them the seeds of a significant questioning of STEM curricula. First, the focus on skills that are transportable is shifting emphases in STEM advocacy towards problem-solving and higher-order skills. Second, an increased pre-occupation with representing 
contemporary professional practices in STEM workplaces has renewed calls for 'authenticity' in situating design and problem-solving, often relating to engineering contexts. Third, the worry about students choosing against STEM pathways has opened up a reconsideration of the nature of science and mathematics curriculum practices, and how these might better accord with contemporary students' learning needs and expectations. Advocacy of STEM in schools has thus opened up contestation between, on the one hand, disciplinary traditions vs. contemporary work practices, and, on the other hand, traditional vs. progressive voices in curriculum framing. This contestation is seen particularly in advocacy of interdisciplinary approaches to STEM curriculum practice.

The argument for interdisciplinary STEM activities often refers to the 'authentic' nature of real-world STEM problems insofar as they mirror the interdisciplinary nature of most STEM professional research and development. This claim is examined further in the next section, but here the circumstance of interdisciplinarity is linked with notions of innovation. Claims are often made that interdisciplinary teams, in STEM or more generally, promote workplace flexibility and innovation. The language of 'flexibility' and 'innovation' is framed within global economic relations and is part of the 'new management systems' terminology. From this viewpoint, there are thus two parts to the argument: the need to bring school STEM practices closer to professional practice, and the promotion of skill sets related to innovation. These visions for interdisciplinary STEM are linked to current international advocacy of curriculum-framing based in competences (PISA 2015 Science Framework; IBE-UNESCO, ND) and also advocacy of closer links between schools and the STEM community (Office of the Chief Scientist, 2014; Tytler et al., 2015). They are therefore informed by particular politico-economic positions that have become the dominant view. OECD and PISA reports, as examples, are replete with such terminology and arguments.

\section{STEM PRACTICE IN SCHOOLS}

In this section, some of the ways in which curriculum contestation, described above, plays out in the development of interdisciplinary STEM curriculum practices in schools is examined. Case studies conducted by one of the authors is drawn on to evidence a set of arguments. These case studies draw on two significant STEM initiatives in Australian secondary schools, each involving data generated through interviews with teachers, students and school leaders, through classroom observation, but also through a collection of artefacts, such as planning documents, reports, and examples of student work. The first case, School A, introduced an interdisciplinary 'STEM-Ed' initiative based around themes such as 'interplanetary travel' or 'designing a garden' with each of the mathematics, science or technology classes, focusing on an aspect of the theme, with some collaborative teaching. In School B, the second case, a group of mathematics teachers introduced interdisciplinary topics, such as the design of a wheelchair ramp, using their knowledge of science and technology design to pursue ideas in each discipline. The following set of arguments focus specifically on the forms of advocacy presented, 
the nature of the practices engaged with, teachers' perceptions of the challenges faced, and students' engagement with learning and the nature of that learning. From these case studies an examination is undertaken of how the forms of advocacy described above from the policy literature, and their contradictions, play out in schools.

Part of the emphasis on new ways of thinking about the outcomes of school study relates to perceptions that students learn differently in a contemporary digitised world. Such a perspective, now dominant in international curriculum policy contexts, is echoed at the local level. A school leader who introduced the STEM-Ed initiative in School A argued thus:

In my teaching career, I began to feel as though traditional approaches to maths teaching were progressively becoming less and less effective, that I was working hard at being excellent at the traditional model, but it was seeming increasingly disconnected from how students liked to learn. I was feeling a generational shift. ... really I think the catalyst was hearing Ian Chubb (Australia's Chief Scientist at the time) speak about STEM and the need for a connected approach to science, technology, engineering, mathematics, and for students to be able to draw up links between those things. I started to think about ... what would that look like in a school setting? (Vice Principal /Mathematics teacher)

In the two STEM professional learning programs studied, change and innovation were seen in a number of respects (Tytler et al., in press). These were in: a) an increasing focus on interdisciplinary activity which was seen as authentic; b) growing confidence with pedagogies that encouraged greater student agency and problem-solving; and c) growing confidence with interactions within the crossdisciplinary school team. Generally, teachers in the case study schools felt that students were more engaged and learning at a deeper level from project based, student-centred STEM activities:

I can see that passion is actually growing within students and they're actually understanding that this works. They're engaging in what they're learning.

And some of the year nines that were in it last year, it really changed their thinking in a way that we've never really seen here in our school before. (STEM teacher from School A)

In a Year 7 module in mathematics in School B, where students were challenged to design a ramp for wheelchairs for a particular location in the school, they experimented with the movement of wheelchairs on slopes, with measurement and recording, and with the geometry of ramps. Teachers argued that students learned to think more deeply about mathematical representational systems for their observations and for analysis:

Even the recording of effort made the girls think deeper, they started to inquire and solve how to best represent it graphically.

One girl came up to me and asked - if she knew the angle and the length, is there a formula to work out the height? This and journal evidence indicate that many girls had 
started to make deep connections between the key maths ideas. (School B mathematics teachers)

The teachers in both schools and also in other schools in the programs, in discussing their experience, emphasized 'relevance' and 'authenticity' as key features of their interdisciplinary work that engaged students in more project-based, problem-based activity than the usual disciplinary curricula. Much of the activity was centred around design (of ramps, carts, gardens, and watering systems from runoff), consistent with STEM advocacy around creative thinking and innovation, and in support of the greater role of engineering highlighted in the STEM acronym. As noted earlier, this focus on critical and creative thinking is the basis for calls to extend the STEM construct to include the creative arts (STEAM), which is often taken to mean the inclusion of innovative technical design within STEM rather than the creative arts more broadly. Creativity, understood in this particular sense of innovation, is thus tied to the wider agenda of wealth-creation, which often can be disassociated from wider social and ethical commitments. Nevertheless, more than a singular commitment to wealth creation, in the specific cases addressed in our analysis, creativity was being generated with ethical purposes in mind. Designing wheel-chair ramps forefronts the purposes of social justice and an inclusive society in educational practice. Such 'real-world' creative problem-solving advances an interdisciplinary STEM that responds to responsible and ethical citizenship and a progressive political outlook and educational praxis (Swanson, Yu \& Mouroutsou, 2017).

A key feature of interdisciplinary STEM advocacy, both at policy level and within schools, is the implied (or explicit) criticism of the prevailing pedagogies in school science and mathematics, which focus strongly on declarative, abstract knowledge rather than the wider competencies applied to problems perceived as relevant by students, implicit in this project/problem-based activity. In other words, traditional mathematics and science teaching tends to be decontextualized, and fails to draw connections between the mathematics and science being taught and their instantiations in social and environmental contexts. This focus on authentic problemsolving need not always cross subject boundaries. The ramp project involved mathematics teachers planning within their subject area, albeit with each of them also having science teaching experience. In another task, they arranged for students to collect data on a height chart located in the school canteen, with volunteers registering both their height and age, with the purpose of devising data representation and analysis processes to predict for parents when they should expect to replace children's uniforms over the secondary school years. This exemplifies the spirit of interdisciplinary STEM within the discipline.

Research has for some time pointed to science and mathematics students' perceptions that the way these school subjects are generally taught lacks relevance to 'real world' contexts and that limited contextualizing pedagogical approaches are applied in the classroom (Lyons, 2006; Tytler et al., 2008). Interdisciplinary advocacy is the latest position in critiquing the narrowness of traditional mathematics and science teaching. Such advocacy promotes a wider framing of school science and mathematics, as exemplified by the Science-Technology-Society 
movement of the 1980s (Yager, 1996), the 'Science for All' and 'Mathematics for All' movements (Fensham, 1985; Tytler, Swanson, Appelbaum, 2015) and 'mathematical literacy' and 'scientific literacy' conceptions of curriculum (Bybee, 1997). Over time, these have all failed to make inroads into the disciplinary traditions of school science and mathematics pedagogy and practice. It remains to be seen whether the current interdisciplinary STEM movement will fare better.

\section{The nature and role of the STEM disciplines in the interdisciplinary setting}

In this section, the research literature is consulted alongside document analysis and empirical case study findings to consider the relationship between disciplinary and interdisciplinary practice and learning. In particular, the nature of interdisciplinarity as currently conceptualized in school curricula is questioned, and the competing agendas at play in advocacy for the different STEM disciplines is reviewed. This pertains to the last research question (RQ5).

Firstly, the argument that because STEM practice 'in the wild' is so often interdisciplinary, STEM in schools should be pursued as an interdisciplinary subject requires interrogation. Secondly, related to the first, the assertion that STEM properly constitutes a meta-discipline needs unpicking. Following theoretical considerations of interdisciplinarity (e.g. Beauchamp \& Beauchamp, 2012), Vasquez (2015) describes four levels of increasing integration of STEM: monodisciplinarity, multidisciplinarity (where subjects are taught separately round a linked theme), interdisciplinarity and transdisciplinarity. The key move from interto trans-disciplinarity involves moving beyond simple linking of disciplinary knowledge around a theme, to activity where new knowledge is created through the specific intersection of disciplinary expertise (Samuels, 2009), or engaging in activities in schools where the problems posed lead students to seek disciplinary knowledge in new settings (Vasquez, 2015). Transdisciplinarity therefore involves a 'coming together' holistically of disciplinary ideas in investigating a problem.

Justification for interdisciplinary curriculum activities in STEM is often framed in terms of the practice of forming interdisciplinary teams in research and development. However, it should be noted that in this case the team comprises disciplinary expertise that intersects within the team, whereas in the school curriculum the presumption is that the learning of disciplinary, and intersecting disciplinary knowledges, occurs in the heads of individuals. The argument can in fact be turned on its head, to advocate that productive interdisciplinarity should be seen in terms of interactions between disciplinary experts, rather than being associated with individuals learning individual interdisciplinary concepts. In professions that represent intersections between the traditional disciplines, such as biochemistry, or dentistry, particular disciplinary depth is required in each of the associated disciplines as well as the way they intersect and relate to each other. This produces a tension. In this sense, albeit more difficult to achieve, in relation to mathematics and science as 'discourses of power' (Swanson, 2005; 2006), we advocate that disciplinary depth goes alongside, not in expense to, interdisciplinary connectedness. 
Conceptions of interdisciplinary interactions are often framed in terms of the intersections within a Venn diagram (Figure 1). It has been argued (Clarke, 2014) that the STEM construct could represent a 'fairly monumental category error' in the sense that the individual STEM disciplines have distinctive epistemic practices with little in common, and that attempting to bring these together raises significant 'boundary problems'. Clarke also points out the complexity of STEM professions, which are quite distinct from the STEM disciplines. Thus, there are substantive theoretical questions about the nature of the suggested intersection of these disciplines that might be thought of as a distinctive 'STEM' disciplinary area. This draws attention to an earlier argument we posed: that the bringing together of Science, Technology, Engineering, and Mathematics, may have wider politicoeconomic purposes and intentions, and may be more about the politics of their new integrations than anything to do with their 'natural' affinities.

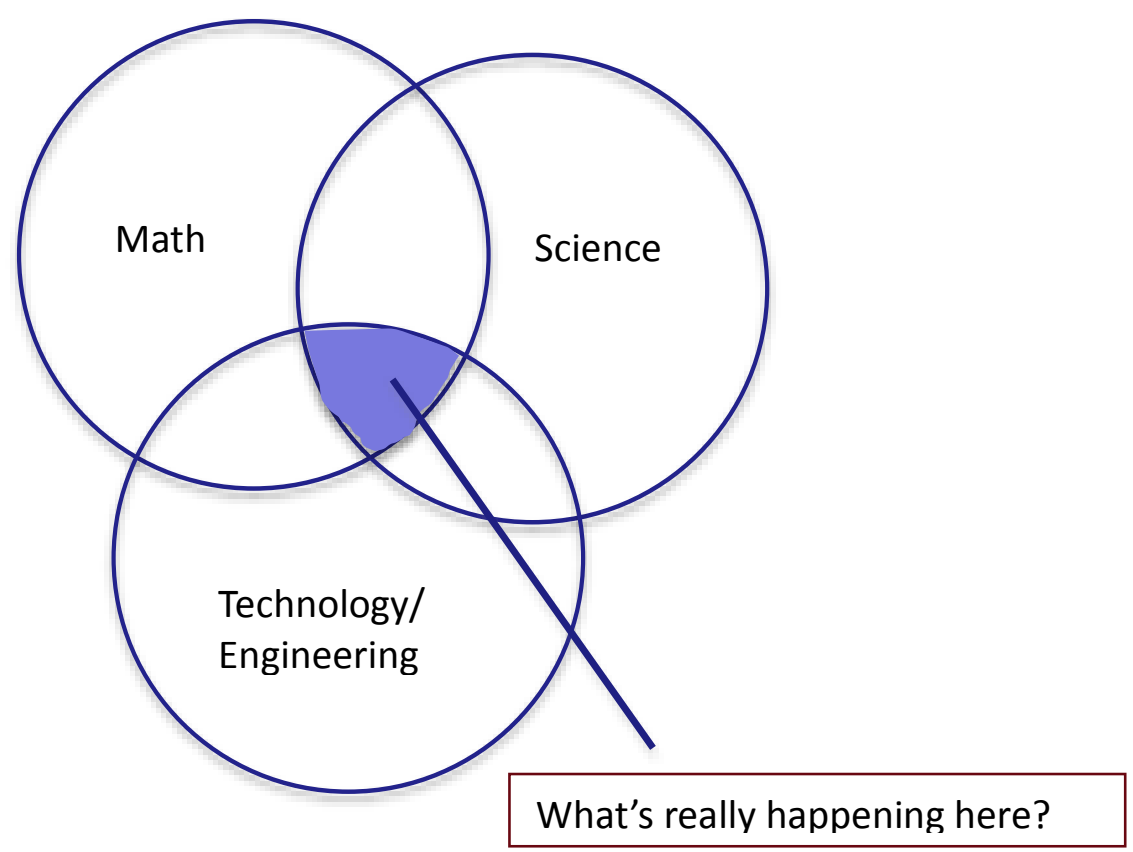

Figure 1: A spatial representation of relations between the STEM disciplines, raising questions about the distinctive nature of STEM meta-disciplinarity.

The spatial metaphor, noted in figure 1, may well be misleading on a number of fronts, including the presumption that disciplines have sharp boundaries in terms of their distinctive and non-intersecting epistemic practices. One line of argument, from critical sociological perspectives, suggests that these epistemic 'boundaries' are socially constructed. Supporting this claim is the fact that disciplines have social, 
cultural and contextual histories that have developed over time in response to particular contextual circumstances. Where an overlap could be argued to exist, following this critical argument, such disciplinary overlaps occur according to contextual, or even socio-political, framings. The intertwining of physics and mathematics would be a case in point, or the history of scientific advancement during the industrial revolution, where engineering and science were closely related. Further, compared to professional practice, school mathematics and science disciplinary curricula represent particularly reified versions of disciplinary practice. There are historical, cultural and political reasons for such instantiations of mathematics and science in schools (Swanson, 2005). Within schools, many of the issues associated with the intersection of the STEM disciplines in curriculum activity are temporal in nature, relating to the ways that individual disciplines interrelate over the immediate short-term, where students draw for instance from both mathematics and science over a scale of minutes to solve a problem. There are also temporal issues in the way that subjects interrelate over the medium term of days and weeks around a STEM project or theme, as a timetable artefact. In the School A STEM-Ed program, teachers planned together and sometimes attended each other's classes. Students perceived relevance flowing from the temporal nature of the arrangement over the medium term:

When you're in STEM, you learn the information, then you get to put it into a practical use in tech. Also, in science we get to do field tests of what we've learned, and the same with maths. It's just very interesting (School A student)

Teachers in this school reported that, if the topics in the subjects were separated in time, for instance the mathematics being taught a term before it was needed for a technology-based project, students would no longer see the relevance of the knowledge.

In week 10 the kids were ... like ... we don't remember anything, because it wasn't valuable to us back then, because we didn't realize that we needed it for our project.

We ... try and apply some of that back in the school with more 'a just in time' approach, like a needs-based approach for learning rather than just 'you need to learn this' (School A teacher)

The previous quotes concerning the power of contextual STEM work for learning mathematics at a deeper level, through grappling with how to represent findings mathematically, points to the possibility of generating longer term temporal coherence. We can see this occurring in the ramp module. In this case, it might form the beginning of a sequence introducing the formalisms of trigonometry, or it may serve a deeper agenda of establishing the processes of mathematical modelling of physical systems (Lehrer, 2009). However, to date, there has been no agreement on how one might build a coherent curriculum sequence around STEM project work that attends to the importance of knowledge-building in the individual STEM disciplines. In fact, there are indications that this agenda may be fundamentally flawed. 
A major US study of the outcomes of interdisciplinary STEM curricula (Honey et al., 2014) found that while these curricular innovations led to enhanced student engagement (as we have illustrated with the Australian cases above), there existed serious questions about the learning outcomes, particularly for mathematics. Lehrer (2016) warns that many STEM-designed projects constitute an 'epistemic stew', designed for engagement but with little regard for the longer-term development of disciplinary concepts. Currently, the authors are engaged in research into models of interdisciplinary mathematics and science that pay attention to the longer-term development of disciplinary foundational concepts. An argument can be made to support the assertion that there is advantage to be gained from the interaction between the subjects as more genuinely representing the core epistemic practices of these disciplines. The key to this argument is a recognition that engagement with the deeper meaning of disciplinary knowledges involves learning to use their core representational systems to flexibly, and more authentically develop explanations and solve problems in a variety of more complex settings. Re-representation, coordination and evaluation of representational tools in meaningful contexts leads to flexibility in learning but also develops meta-representational competence (diSessa, 2004) that underpins epistemic knowledge within individual STEM disciplines. Thus, there is a sound argument for working with students to mathematically model natural systems, paying particular attention to constructs of measurement, data variation, sampling, and spatial patterns that arise naturally from these crossdisciplinary contexts. Further, applying these disciplinary ideas in authentic contexts brings in other knowledges and values. In the wheelchair ramp activity, for instance, students experimented with the practicalities of wheelchair motion at different slopes and with access issues more generally, such that teachers commented on the societal and empathetic learnings associated with the STEM module. This again testifies to the wider purposes and learnings that arise from integrated, interdisciplinary STEM learning, ones that affirm personal, community and ethical citizenship, and that have a focus on political responsibility, inclusion, and the ideals of a progressive society over-and-above the scientific aspects of the learning taking place (Swanson, Yu, \& Mouroutsou, 2017).

\section{CONCLUSION}

In this chapter, the authors reviewed the key catalysts for STEM education policy advocacy in its global context, deploying Australian examples in the main to exemplify their arguments. In the process, contradictions and possibilities for practice in schools were highlighted, particularly for interdisciplinary versions of STEM. Some cases of school practices and experiences were examined to highlight both the challenges and possibilities for productive STEM curriculum innovation. Finally, questions about the construct of interdisciplinarity and how this may potentially interfere with productive learning was raised. 


\section{A contradiction in STEM advocacy}

The key policy arguments for STEM in schools are dominantly framed in terms of the need for a professional STEM workforce to contribute to national wealth creation. In this sense, STEM advocacy is part of a global movement that promotes an instrumentalist view of the purposes of schooling, one that serves the interests of national and global capital to the possible detriment of alternative schooling purposes that advocate instead the development of the person/community and of personal/community qualities aimed at the wellbeing of citizens. This narrow economically-driven advocacy, on its own, has no wider implications for the nature of STEM school pedagogy and practice except that STEM subjects are positioned to prepare 'enough' students 'adequately' for future work. The agenda is coercive, fundamentally conservative with respect to curriculum, and at face-value is opposed to wider educative conceptions of schooling that aim at the holistic and critical development of personhood.

In its dominant mode, a strong and increasingly pervasive strand of STEM advocacy argues for the need to develop in students a set of 'skills' and 'competencies' that are seen as fuelling the engines of wealth creation through a focus on innovation and entrepreneurship. The advocacies of 'higher order' and creative thinking, design thinking, non-routine problem solving, and systems thinking, framed around the push for STEM education, all follow this economicallydriven agenda in the main. This focus is aligned with increasing advocacy of competency-based curricula, for instance by the OECD, or the International Bureau of Education, and implies a need to reconceptualize traditional curriculum framings in the direction of STEM integration. STEM advocacy proceeds through the implied alignment of STEM subjects with these skills. However, this has created a double gesture: on the one hand, it has led to calls for a change in focus in the way STEM subjects are taught in order to more explicitly attend to such skills development, premised on the assumption that these skills are, and should be, the driving purpose of STEM advocacy in schools; and on the other hand, the need for STEM in respect of a wider consideration of its educational purposes in bringing 'relevance', 'authenticity' and meaning to students lives in shaping their identities.

In other terms, within this advocacy lies the seeds of a set of contradictions in relation to the contested ground of STEM Education. The flip side of this focus on skills for wealth creation, for instance, is the need to develop in students the skills and capabilities that will prepare them for productive, but also fulfilling lives. While the STEM focus is couched in instrumentalist terms, it can also be translated into a call for a more personally meaningful and relevant education for future citizens, albeit within the restricted scope of STEM subjects. This is particularly true for arguments for interdisciplinary STEM, where questions of authenticity and relevance are driving a challenge to traditional forms of disciplinary content and pedagogy. The other contestation playing out within STEM advocacy is the challenge to have the curriculum better represent contemporary workplace practices and everyday life, rather than being decontextualized and grounded in traditional or 'classical' conceptions of subjects sustained by the academy as a consequence of socio-historical and political forces. 


\section{Opportunities and challenges in interdisciplinary STEM curricula}

Within this contested policy space, snapshots from case studies of schools undergoing innovation in interdisciplinary STEM curricula was presented. This approach was undertaken to explore the challenges and potentialities of interdisciplinary STEM practices. In the Australian case studies, teachers within the two schools (A and B) voiced their commitment to change premised on a strong belief that students' learning needs changing commensurately with school curricula change. For teachers and students alike, curricula and pedagogical changes need to take into consideration students' deeper learning and a greater meaningfulness in learning approaches. There was a strong focus on engagement through the relevance that students were able to bring to their science and mathematics learning, especially when they invented or applied science or mathematics knowledge to project-based design work. Teachers claimed that they witnessed improvement in learning outcomes and in attitudes to science and mathematics. The change to problem-based curricula saw a shift towards student-centred pedagogies in line with more progressive agendas, and also attention to problem-solving and investigative activities, developing teamwork and wider societal commitments. There was some indication that there were greater opportunities to link interdisciplinary STEM to issues of global significance, or to ethical and inclusive societal ideals, so that interdisciplinary STEM learning effected opportunities for wider educational purposes.

\section{The STEM disciplines and epistemic integrity}

From these cases and from the literature, an argument can be made to support the assertion that, while these particular interdisciplinary projects are engaging and productive in the medium term, a convincing interdisciplinary STEM curriculum is yet to be conceptualized. The problem lies in a failure to identify a coherent STEM epistemic practice distinct from the epistemic practices of the individual STEM disciplines, which are both particular and different. Thus, interdisciplinary practices represented by such cases cannot be usefully conceived of as the spatial overlap of individual disciplinary epistemic practices, but rather should be thought of as involving the interleaving of disciplinary ways of thinking over different temporal scales.

Finally, an argument was advanced for disciplinary knowledge in the individual STEM disciplines as being core to successful interdisciplinary problem-solving, and that a more meaningful conception of interdisciplinary STEM lies in the ways it represents authentic invention, coordination and evaluation of disciplinary ideas in complex settings. A further allied argument was provided suggesting that the challenge for policy advocacy of interdisciplinary STEM lies in challenging existing, reified versions of contemporary disciplinary practices that have been preserved in schools, and the decontextualized, procedural teaching practices that accord them and are prevalent world-wide. Underscoring interdisciplinary STEM approaches is the search for authenticity, ethical responsiveness and 'relevance' for students grounded in contemporary practices and dealing with 'real-world' challenges. From this perspective, the utilitarian and regressive policy framings currently being used 


\section{TYTLER \& SWANSON}

to promote STEM within globalizing modernism can be productively turned to wider purposes in schools, emphasizing the development of creative and critical thinking and ethical dispositions that should be central to liberatory and progressive schooling.

\section{REFERENCES}

Australian Government, 2015. Vision for a Science Nation, consultation paper, http://www.science.gov.au/scienceGov/news/Documents/VisionForAScienceNationRespondingToS TEMAustraliasFuture.pdf.

Beauchamp, M., \& Beauchamp, C. (2012). Understanding the neuroscience and education connection: themes emerging from a review of the literature. Neuroscience in education: the good, the bad, and the ugly, 13-30.

Berlin, D. F., \& Lee, H. (2003). A bibliography of integrated science and mathematics teaching and learning literature, Vol. 2: 1991-2001. School Science and Mathematics Association Topics for Teachers Series Number 7. Columbus, OH: ERIC Clearinghouse for Science, Mathematics, and Environmental Education.

Berlin, D. F., \& Lee, H. (2005). Integrating science and mathematics education: Historical analysis. School Science and Mathematics, 105(1), 15-24.

Brown, P., Ashton, D.N., \& Lauder, H. (2012), The Global Auction: The broken promises of education, jobs and incomes, Oxford University Press, Oxford

Bybee, R. (1997). Achieving scientific literacy: From purposes to practical action. Portsmouth, NH: Heinemann.

Bybee, R. (2013). The Case for Education: Challenges and Opportunities. http://static.nsta.org/files/PB337Xweb.pdf.

Clarke, D. (2014). Disciplinary Inclusivity in Educational Research Design: Permeability and Affordances in STEM Education. Invited keynote at the International STEM conference, Vancouver, July 2014. http://www.djclarke.iccr.edu.au/

Commonwealth Bank (2017), The Commonwealth Bank jobs and skills of the future report, Retrieved from:https://rossdawson.com/wp-content/uploads/2017/11/Commonwealth-Bank_Jobs-and-Skillsof-the-Future-Report November-2017.pdf

Coppola, F. (2018). Is Austerity really Coming To An End In The UK?. Forbes, October 31, 2018, 2:34 pm. Available: https://www.forbes.com/sites/francescoppola/2018/10/31/is-austerity-really-comingto-an-end-in-the-uk/\#446f576a7c2f

diSessa, A. (2004). Metarepresentation: Native competence and targets for instruction. Cognition and Instruction, 22(3), 293-331.

Duncan, A. (2014). The Threat of Educational Stagnation and Complacency, The Education Digest, Ann Arbor, 79(7): 23 - 27 (March 2014).

Education Council, 2015. The National Stem School Education Strategy 2016-2026, http://www.educationcouncil.edu.au/site/DefaultSite/filesystem/documents/National\%20STEM\%20 School\%20Education\%20Strategy.pdf.

English, D. L. (2016a). STEM education K-12: perspectives on Integration. English International Journal of STEM Education, 3(3). doi: 10.1186/s40594-016-0036-1

English, L. (2016). Targeting all of STEM in the primary school: Engineering design as a foundational process. Australian Council for Educational Research. Research Conference 2016., http://research.acer.edu.au/cgi/viewcontent.cgi?article=1298\&context=research conference

English, L. D., \& King, D. T. (2015). STEM learning through engineering design: fourth-grade students' investigations in aerospace. International Journal of STEM Education, 2(14). doi: 10.1186/s40594015-0027-7

Fensham, P. (1985). Science for all: a reflective essay. Journal of Curriculum Studies, 17 (4), 415-435. 


\section{PURPOSES AND POTENTIAL OF INTERDISCIPLINARY STEM}

Foundation for Young Australians (FYA) (2017), The New Work Order: Ensuring young Australians have skills and experience for the jobs of the future, not the past. Retrieved from http://www.fya.org.au/wp-content/uploads/2015/08/fya-future-of-work-report-final-lr.pdf

Hajkowicz, S.A., Reeson, A., Rudd, L., Bratanova, A., Hodgers, L., Mason, C., Boughen, N. (2016), Tomorrow's Digitally Enabled Workforce: Megatrends and scenarios for jobs and employment in Australia over the coming twenty years. CSIRO, Brisbane.

Herschbach, D. R. (2011). The STEM initiative: Constraints and challenges. Journal of STEM Teacher Education, 48(1), 96-122.

Hilton, M. (2010). Exploring the Intersection of Science Education and 21st Century Skills: A Workshop Summary. National Research Council. Washington, DC: The National Academies Press. https://www.nap.edu/catalog/12771/exploring-the-intersection-of-science-education-and-12721stcentury-skills.

Honey, M., Pearson, G., \& Schweingruber, H. (2014). STEM Integration in K-12 Education: Status, Prospects, and an Agenda for Research. https://www.nap.edu/read/18612/chapter/18611.

International Bureau of Education (IBE-UNESCO) (ND). Competency-based curriculum. http://www.ibe.unesco.org/en/glossary-curriculum-terminology/c/competency-based-curriculum

Lacey, T. A., \& Wright, B. (2009). Occupational employment projections to 2018. Monthly Labor Review, 132(11), 82-123.

Langdon, D., McKittrick, G., Beede, D., Khan, B., \& Doms, M. (2011). STEM: Good Jobs Now and for the Future. Washington, DC: U.S. Department of Commerce, http://www.esa.doc.gov/sites/default/files/stemfinalyjuly14 11.pdf.

Lehrer, R. (2009). Designing to develop disciplinary dispositions: modeling natural systems. American Psychologist, 64(8), 759.

Lyons, T. (2005). Different countries, same science classes: Students' experiences of school science in their own words. International Journal of Science Education, 28 (6), 591-614.

Lyons, T. (2006). Different countries, same science classes: Students' experiences of school science in their own words. International journal of science education, 28(6), 591-613.

Marginson, S., Tytler, R., Freeman, B., \& Roberts, K. (2013). STEM: Country Comparisons International comparisons of science, technology, engineering and mathematics (STEM) education. http://www.acola.org.au/PDF/SAF02Consultants/SAF02_STEM_\%20FINAL.pdf.

Moyer-Packenham, P. S., Anastasis, K., Johanna, J. B., Faye, H., \& Irby, N. (2008). Participation by STEM faculty in mathematics and science partnership activities for teachers. Journal of STEM Education: Innovations and Research, 10(2).

National Academies Committee on Science, Engineering, and Public Policy (COSEPUP). (2006). Rising above the gathering storm: Energizing and employing America for a brighter economic future. Retrieved September 5, 2006 from http://www.nap.edu/catalog/11463.html\#orgs

National Research Council, National Academy of Engineering (2009). Engineering in K-12 education: Understanding the status and improving the prospects. National Academies Press

Next Generation Science Standards, USA, 2014. http://www.nextgenscience.org/.

OECD (2015). Improving schools in Scotland: An OECD perspective. Paris: OECD.

Office of the Chief Scientist (2013). Science, Technology, Engineering and Mathematics in the National Interest: A Strategic Approach, http://www.chiefscientist.gov.au/wpcontent/uploads/STEMstrategy290713FINALweb.pdf.

Office of the Chief Scientist (2014). Science, Technology, Engineering and Mathematics: Australia's Future, http://www.chiefscientist.gov.au/wpcontent/uploads/STEM AustraliasFuture Sept2014 Web.pdf.

Olson, S., O., \& Gerardi, D. R. (February 2012). Engage to Excel: Producing One Million Additional College Graduates with Degrees in Science, Technology, Engineering, and Mathematics. Report to the President. https://www.whitehouse.gov/sites/default/files/microsites/ostp/pcast-engage-to-excelfinal 2-25-12.pdf.

Perryman, M. R. (July 2014). STEM and the Economy, . The Perrynam Group, an Economic and Financial Analysis Firm, https://www.perrymangroup.com/2014/07/18/stem-and-the-economy/. 
TYTLER \& SWANSON

PISA (2015). PISA 2015 Science Framework. http://www.oecd.org/publications/pisa-2015-assessmentand-analytical-framework-9789264281820-en.htm

PwC Australia, 2015. A smart move. Future-proofing Australia's workforce by growing skills in science, technology, engineering and maths (STEM), www.pwc.docalytics.com/v/a-smart-move-pwc-stemreport-april-2015.

Rumbens, D. (2015). What to do about our STEM problem http://blog.deloitte.com.au/greendot/2015/2005/2012/what-to-do-about-our-stemproblem/\#.V2018zblv12094ol.

Samuels, B. (2009). Can the differences between education and neuroscience be overcome by mind, brain, and education? Mind, Brain, and Education, 3(1), 45-55

Sundararajan, A. (2017). 'The Future of Work: The digital economy will sharply erode the traditional employer-employee relationship', Finance and Development, International Monetary Fund (IMF), $54 / 2$

Swanson D.M. (2005) School Mathematics: Discourse and the Politics of Context. In: Chronaki A, Christiansen IM (ed.). Challenging Perspectives on Mathematics Classroom Communication. International Perspectives on Mathematics Education - Cognition, Equity \& Society, Greenwich, CT: Information Age, pp. 261-294.

Swanson D.M. (2006) Power and Poverty - Whose, Where, and Why?: School mathematics, context and the social construction of "disadvantage" In: Novotná J, Moraová H, Krátká M, Stehlíková N (ed.) Proceedings 30th Conference of the International Group for the Psychology of Mathematics Education, Volume 5, Prague, Czech Republic: Charles University. 30th Annual Meeting of the International Group for the Psychology of Mathematics Education, 16.7.2014 - 21.7.2006, Prague, Czech Republic, pp. (5-217)-(5-224).

Swanson, D.M. (2013a). The owl spreads its wings: global and international education within the local from critical perspectives. In: Hebert Y, Abdi AA (ed.). Critical Perspectives on International Education. Comparative and International Education: A Diversity of Voices, 15, Rotterdam: Sense, pp. 333-348.

Swanson, D.M. (2013b). Neoliberalism, education, and citizenship rights of unemployed youth in postapartheid South Africa, Sisyphus - Journal of Education, 1 (2), pp. 194-212.

Swanson, D.M. (2017). Mathematics Education and the Problem of Political Forgetting: In Search of Research Methodologies for Global Crisis, Journal of Urban Mathematics Education, 10 (1), pp. 7 15.

Swanson D.M., Yu, H. \& Mouroutsou, S. (2017) Inclusion as Ethics, Equity and/or Human Rights? Spotlighting School Mathematics Practices in Scotland and Globally, Social Inclusion, 5 (3), pp. $172-$ 182. https://doi.org/10.17645/si.v5i3.984.

Thomson, Sue; De Bortoli, Lisa; and Underwood, Catherine, "PISA 2015: Reporting Australia's results" (2017). https://research.acer.edu.au/ozpisa/22

Tytler, R., Osborne, J., Williams, G., Tytler, K., \& Cripps Clark, J. (2008). Opening up pathways: Engagement in STEM across the Primary-Secondary school transition. Canberra: Australian Department of Education, Employment and Workplace Relations.

Tytler, R., Swanson, D.M., \& Appelbaum, P. (2015). Subject matters of science, technology, engineering, and mathematics. In, M. F. He, B. D. Schultz, \& W. H. Schubert (Eds), The Sage Guide to Curriculum in Education (Ch. 4, pp. 27-35). Thousand Oaks, CA: Sage. (Release date: August 2015).

Tytler, R., Symington, D., Williams, G., White, P., Campbell, C., Chittleborough, G., Upstill, G., Roper, E., \& Dziadkiewicz (2015). Building productive partnerships for STEM Education: Evaluating the model and outcomes of the Scientists and Mathematicians in Schools program. Melbourne: Deakin University. Available at: http://www.scientistsinschools.edu.au/downloads/SMiSEvaluationReport2015.pdf

Tytler, R., Williams, G., Hobbs, L., \& Anderson, J. (in press). Challenges and opportunities for a STEM interdisciplinary agenda, In B. Doig \& J. Williams et al. (Eds) Interdisciplinarity and Mathematics Education. Springer ICME series. 
PURPOSES AND POTENTIAL OF INTERDISCIPLINARY STEM

U.S. Department of Education (2000). Before It's Too Late: A Report to the Nation from the National Commission on Mathematics and Science Teaching for the 21st Century. Department of Education, Washington, DC. https://eric.ed.gov/?id=ED441705

Vasquez, J. (2015). Beyond the acronym. Educational Leadership, 11-15.

Yager, R. E. (Ed.). (1996). Science/technology/society as reform in science education. SUNY Press.

\section{AFFILIATIONS}

Russell Tytler

School of Education

Deakin University, Australia

Dalene Swanson

Faculty of Social Sciences

University of Stirling, Scotland 